\title{
Mathematical modeling of nanodispersed hardening of FCC materials
}

\author{
Oleg Matvienko ${ }^{1,2} \cdot$ Olga Daneyko $^{2} \cdot$ Tatyana Kovalevskaya $^{2}$
}

Received: 3 January 2018/Revised: 30 March 2018/Published online: 9 June 2018

(C) The Chinese Society for Metals and Springer-Verlag GmbH Germany, part of Springer Nature 2018

\begin{abstract}
The plastic deformation of the pipe made of Cu-based alloy hardened by incoherent nanoparticles and subjected to the uniform internal pressure was investigated. The limits of elastic and plastic resistance are determined. The insignificant excess in the limit of the elastic resistance enables the plastic deformation in the most part of the pipe wall. The densities of shear-forming dislocations and prismatic dislocation loops are higher in alloys strengthened with coarse particles than in alloys strengthened with fine particles. At small distances between the strengthening particles, this effect is the most pronounced.
\end{abstract}

Keywords Deformation - Dislocation · Dispersion-strengthening · Nanoparticles · Hardening - Stress · Strain · Elastic-plastic deformation · Pipe

List of symbols
$a$
$\dot{a}$
$b$
$D$
$F$

$G$
$k$
$P_{\mathrm{as}}$
$Q_{j}=Z_{j} v_{\mathrm{D}} \exp \left(-U_{j}^{(\mathrm{m})} / k T\right)$
$q$
$r_{\mathrm{a}}$
$T$
$U_{j}^{(\mathrm{m})}$

Deformation intensity

Deformation strain rate

Burgers vector

Diameter of the shear zone

The shape of the dislocation

loops and their distribution in

the shear zone

The shear modulus

The Boltzmann constant

The probable annihilation of screw dislocations

The kinetic coefficient

Intensity of point defect

generation

Critical capture radius

Temperature

Activation energy of the $j$ th

type point defect migration

\section{$\tau_{\mathrm{f}}$}

$<\chi>$

$\omega_{\mathrm{s}}$
The number of places for the $j$ th type point defect jump The dislocation interaction Reacting dislocation The particle diameter Distance between particles of the second phase The Debye frequency The forest dislocation Dislocation density Dislocation density in dipole configurations Density of prismatic dislocation loops Athermal resistance to the dislocation movement Excess stress over static resistance to the dislocation movement

The friction stress The geometry of dislocations on particles

The amount of screw dislocations

Oleg Matvienko

matvolegv@mail.ru

1 National Research Tomsk State University, Tomsk, Russia 634050

2 Tomsk State University of Architecture and Building, Tomsk, Russia 634003 


\section{Introduction}

Dispersion hardened materials play an important role in the problem of improving the reliability and reducing materials consumption of machines and mechanisms. Nanosize particles contribute to the matrix strengthening providing resistance to dislocation motion according to Orowan's theory [1]. Their distinctive peculiarity and advantage in comparison with reinforced and laminated materials are the isotropy of mechanical properties as well as high plasticity and strength. Investigations [2-5] show that dispersionstrengthened alloys are characterized by relatively high tensile strength and creep.

One of the first studies in which the foundations of the physical theory of plasticity and strain hardening were investigated are the works by Orowan, [1] Ashby [6-8], Hirsch [9-11], Humphreys [12-14]. In the review [15], the processes that can occur in dispersed-hardened materials during plastic deformation were discussed. The formation and stability of plastic zones around particles of the second phase were described and competitive processes of formation of voids and diffusion relaxation were considered. In the literature [16], it was concluded that uniform plastic deformation is preferred for dispersion-hardened materials. Heterogeneous deformation occurs if the dispersion-hardened materials contain small dislocation loops. The investigation [17] deals with aspects of the deformation behavior of dispersion-hardened aluminum materials during uniaxial creep in a broad temperature range. Results of investigation demonstrate that the threshold stress decreases considerably with increasing temperature. The authors of the investigation [18] focused on examination of materials of submicron matrix grain size strengthened with of nanosize particles. The obtained results show a possibility for the significant improvement of properties of the microcomposites. The paper [19] described the processing and microstructural characterization of two dispersionstrengthened alloys of nominal-composition $\mathrm{Cu}-2.5 \mathrm{vol} \%$ $\mathrm{TiC}-2.5 \mathrm{vol} \% \mathrm{Al}_{2} \mathrm{O}_{3}$. It was shown that at high temperature dispersoids act as effective pinning sites for dislocations, thus controlling slip and grain growth. In the literature [20], some questions on the development of the cobalt-based composite material dispersion-hardened by nanoparticles were considered. It is shown that the obtained dispersionhardened alloy possesses high indices of mechanical properties. The results of the studies of the effect of the nanodiamonds additions on physico-mechanical properties of the drilling tool metal matrix have discussed in the literature [21]. The optimal concentration of nanodiamond powder additives in the composition of a hard alloy mixture was defined. The addition of $1-2 \mathrm{wt} \%$ nanodispersed diamonds has been shown to contribute to binding oxygen in the thermooxidation of diamond in the course of the tool manufacture, which makes it possible to reduce the amount of pores in the matrix material structure and to increase its density by $1.7 \%$ and hardness by $24.3 \%$.

Up to now, no unified theoretical model of dispersionhardening of alloys by nanodimensional particles exists. This is associated with the complexity of taking into account numerous factors affecting the character of the interaction of particles with moving dislocations, which determines the dispersion-hardened effect. However, in a series of works, such interaction has been theoretically evaluated. For example, the authors [22, 23] represented the equation of the dislocation shear stress $\left(\tau_{k}\right)$ in a dispersion-hardened material as:

$\tau_{k}=C V_{r}^{1.5} n G_{\mathrm{m}} \frac{b}{r}$,

where $C$ is a constant, $V_{r}$ is the bulk fraction of particles, $n$ is the number of dislocation rings around particles, $G_{\mathrm{m}}$ is the shear modulus of the matrix material, and $r$ is the mean size of a particle in the slip plan; $b$ is the length of the Burgers vector of the dislocation in the metal matrix.

Mathematical modeling of composites hardened by nanoparticles with a metal matrix was considered [24]. The authors covered in detail the effect of the bulk content, distribution, and morphology of nanoparticles per average path length of a dislocation in the alloy $(L)$. The authors revealed that the uniform distribution of grains in the matrix gives the smallest value of $L$. An increase in the bulk content of nanoparticles from 1 to 7 vol\% decreases the average path length of the dislocation by $50 \%$, and if their fraction exceeds 7 vol\%, the value of $L$ is almost invariable.

The mathematical model of plastic deformation of dispersed-hardened materials is developed by Kovalevskaya and Daneyko [25-29]. This model is based on the equations of the balance of deformation defects of various types, taking into account their transformation in the process of plastic deformation. On the basis of this model [26], they studied the effect of the scale characteristics of the strengthening phase, temperature and strain rate on the evolution of the dislocation subsystem and deformation hardening of the alloy strengthened by particles. It is found that in materials with a nanoscale hardening phase, more intensive strain hardening is observed than in materials containing submicron particles at the same volume fraction of the hardening phase [28].

The present work seeks to investigate the plastic deformation of the pipe made of $\mathrm{Cu}$-based alloy hardened by incoherent nanoparticles and subjected to the uniform internal pressure. The mathematical model is based on the equations of the balance of the defect structure [27, 29] and principles of mechanics of deformable solids [30-32]. 


\section{Strain hardening modeling}

The modeling of plastic deformation and strain hardening implies that during plastic shear in incoherent nanoparticlestrengthened FCC alloys, the formation of a shear zone is observed with such deformation defects as shear dislocations with density $\rho_{\mathrm{m}}$, vacant and interstitial prismatic dislocation loops $\rho_{\mathrm{p}}$, point defects (interstitial atoms with concentration $c_{\mathrm{i}}$ ), monovacancies (with concentration $c_{\mathrm{v}}$ ), and divacancies (with concentration $c_{2 \mathrm{v}}$ ). Equations of the balance of the dislocation structure make it possible to determine the density of dislocations, as well as the concentration of point defects. These equations have the form [33]:

$$
\begin{aligned}
\frac{\mathrm{d} \rho_{\mathrm{m}}}{\mathrm{da}=} & \left(1-\omega_{\mathrm{s}} P_{\mathrm{as}}\right) \frac{F}{D b}-\frac{2}{\dot{a}}\left(1-\omega_{\mathrm{s}}\right) \rho_{\mathrm{m}}^{2} b \min \left(r_{\mathrm{a}}, \rho_{\mathrm{m}}^{-1 / 2}\right) \\
& \left(c_{2 \mathrm{v}} Q_{2 \mathrm{v}}+c_{1 \mathrm{v}} Q_{1 \mathrm{v}}+c_{\mathrm{i}} Q_{\mathrm{i}}\right)+ \\
& +\frac{2 \alpha}{\dot{a}} b \sqrt{\rho}\left(\rho_{\mathrm{p}}^{\mathrm{v}}\left(c_{1 \mathrm{v}} Q_{1 \mathrm{v}}+c_{2 \mathrm{v}} Q_{2 \mathrm{v}}\right)+\rho_{\mathrm{p}}^{\mathrm{i}} c_{\mathrm{i}} Q_{\mathrm{i}}\right) \\
& +\frac{2 b}{\dot{a} r_{\mathrm{a}}}\left(\rho_{\mathrm{d}}^{\mathrm{i}} c_{\mathrm{i}} Q_{\mathrm{i}}+\rho_{\mathrm{d}}^{\mathrm{v}}\left(c_{1 \mathrm{v}} Q_{1 \mathrm{v}}+c_{2 \mathrm{v}} Q_{2 \mathrm{v}}\right)\right), \\
\frac{\mathrm{d} \rho_{\mathrm{p}}^{\mathrm{i}}}{\mathrm{d} a}= & \frac{<\chi>\delta}{2 \Lambda_{\mathrm{p}}^{2} b}-\frac{2 \alpha}{\dot{a}} \sqrt{\rho} \rho_{\mathrm{p}}^{\mathrm{i}} b\left(2 c_{2 \mathrm{v}} Q_{2 \mathrm{v}}+c_{\mathrm{i}} Q_{\mathrm{i}}+2 c_{1 \mathrm{v}} Q_{1 \mathrm{v}}\right), \\
\frac{\mathrm{d} \rho_{\mathrm{p}}^{\mathrm{v}}}{\mathrm{d} a}= & \frac{<\chi>\delta}{2 \Lambda_{\mathrm{p}}^{2} b}-\frac{2 \alpha}{\dot{a}} \sqrt{\rho} \rho_{\mathrm{p}}^{\mathrm{v}} b\left(c_{2 \mathrm{v}} Q_{2 \mathrm{v}}+2 c_{\mathrm{i}} Q_{\mathrm{i}}+c_{1 \mathrm{v}} Q_{1 \mathrm{v}}\right), \\
\frac{\mathrm{d} \rho_{\mathrm{d}}^{\mathrm{v}}}{\mathrm{d} a}= & \frac{1}{\Lambda_{\mathrm{p}} b}-\frac{2 b}{\dot{a} r_{\mathrm{a}}} \rho_{\mathrm{d}}^{\mathrm{v}}\left(c_{2 \mathrm{v}} Q_{2 \mathrm{v}}+c_{\mathrm{i}} Q_{\mathrm{i}}+c_{1 \mathrm{v}} Q_{1 \mathrm{v}}\right), \\
\frac{\mathrm{d} \rho_{\mathrm{d}}^{\mathrm{i}}}{\mathrm{d} a}= & \frac{1}{\Lambda_{\mathrm{p}} b}-\frac{2 b}{\dot{a} r_{\mathrm{a}}} \rho_{\mathrm{d}}^{\mathrm{i}}\left(c_{2 \mathrm{v}} Q_{2 \mathrm{v}}+c_{\mathrm{i}} Q_{\mathrm{i}}+c_{1 \mathrm{v}} Q_{1 \mathrm{v}}\right), \\
\frac{\mathrm{d} c_{\mathrm{i}}}{\mathrm{d} a}= & \frac{\tau_{\mathrm{dyn}}}{G}-\frac{c_{\mathrm{i}}}{\dot{a}}\left[\left(\left(1-\omega_{\mathrm{s}}\right) \rho_{\mathrm{m}}+\rho_{\mathrm{p}}+\rho_{\mathrm{d}}\right) b^{2} Q_{\mathrm{i}}\right. \\
& \left.+Q_{1 \mathrm{v}} c_{1 \mathrm{v}}+Q_{2 \mathrm{v}} c_{2 \mathrm{v}}+Q_{\mathrm{i}}\left(c_{1 \mathrm{v}}+c_{2 \mathrm{v}}\right)\right], \\
\frac{\mathrm{d} c_{1 \mathrm{v}}}{\mathrm{d} a}= & \frac{q \tau_{\mathrm{dyn}}}{6 G}-\frac{1}{\dot{a}}\left[\left(\left(\left(1-\omega_{\mathrm{s}}\right) \rho_{\mathrm{m}}+\rho_{\mathrm{p}}+\rho_{\mathrm{d}}\right) b^{2}\right.\right. \\
& \left.+c_{\mathrm{i}}+c_{1 \mathrm{v}}\right) Q_{1 \mathrm{v}} c_{1 \mathrm{v}}+Q_{\mathrm{i}} c_{\mathrm{i}} c_{1 \mathrm{v}}- \\
& \left.-\left(Q_{2 \mathrm{v}}+Q_{\mathrm{i}}\right) c_{\mathrm{i}} c_{2 \mathrm{v}}\right], \\
\frac{\mathrm{d} c_{2 \mathrm{v}}}{\mathrm{d} a}= & \frac{5 q \tau_{\mathrm{dyn}}}{6 G}-\frac{1}{\dot{a}}\left[\left(\left(\left(1-\omega_{\mathrm{s}}\right) \rho_{\mathrm{m}}+\rho_{\mathrm{p}}+\rho_{\mathrm{d}}\right) b^{2}+c_{\mathrm{i}}\right) Q_{2 \mathrm{v}} c_{2 \mathrm{v}}\right. \\
& \left.+Q_{\mathrm{i}} c_{\mathrm{i}} c_{2 \mathrm{v}}-Q_{1 \mathrm{v}} c_{1 \mathrm{v}}^{2}\right], \\
\dot{a}= & \frac{8}{\pi} \frac{v_{\mathrm{D}} B \beta_{\mathrm{r}}^{1 / 2}}{\xi^{1 / 6} F\left(1-\beta_{\mathrm{r}}\right)} \frac{\tau^{3}\left(\left(\left(1-\beta_{\mathrm{r}}\right) \rho_{\mathrm{m}}+\rho_{\mathrm{p}}+\rho_{\mathrm{d}}\right)\left(\tau-\tau_{a}\right)\right)^{1 / 3}}{G^{4 / 3} b^{1 / 3}\left(\tau^{2}-G^{2} b^{2} \xi \beta_{\mathrm{r}} \rho_{\mathrm{m}}\right) \rho_{\mathrm{m}}^{1 / 2}} \times \\
& \times \exp \left[-\frac{0,2 G b^{3}-\left(\tau-\tau_{\mathrm{a}}\right) \Lambda b^{2}}{k T}\right] .
\end{aligned}
$$

In a non-deformable material $(a=0)$, the dislocations density and concentration of point defects are equal: $c_{j}(0)=\exp \left(-U_{j} / k T\right), \quad j=\mathrm{i}, 1 \mathrm{v}, 2 \mathrm{v}$, $\rho_{\mathrm{m}}(0)=10^{12} \mathrm{~m}^{-2}, \rho_{\mathrm{p}}(0)=\rho_{\mathrm{d}}(0)=0$.

The principal calculations are carried out at the parameter values for single-crystals of particle-reinforced $\mathrm{Cu}$ based alloys [26, 30].
The results of mathematical modeling, obtained on the basis of the solution of the Eq. (1), show that in dispersedhardened materials with a nanodispersed hardening phase, the flow stress is much higher than that in materials with larger particles with the same volume fraction of the strengthening phase. This is especially noticeable at low degrees of deformation and at temperatures above room temperature.

An investigation of the effect of the scale characteristics of the strengthening phase on the strain hardening curves of copper-based materials with an incoherent strengthening phase showed that strain hardening increases with increasing particle size or a decreasing in the distance between them at all deformation temperatures (Fig. 1a-c). The dislocation dipoles are not formed throughout the entire process of plastic deformation in a material with nanosize particles of the strengthening phase in a wide range of temperatures (Fig. $1 \mathrm{j}-1$ ). There is a decrease in the flow stress, dislocation density in the prismatic loops, and the concentration of point defects with an increase in

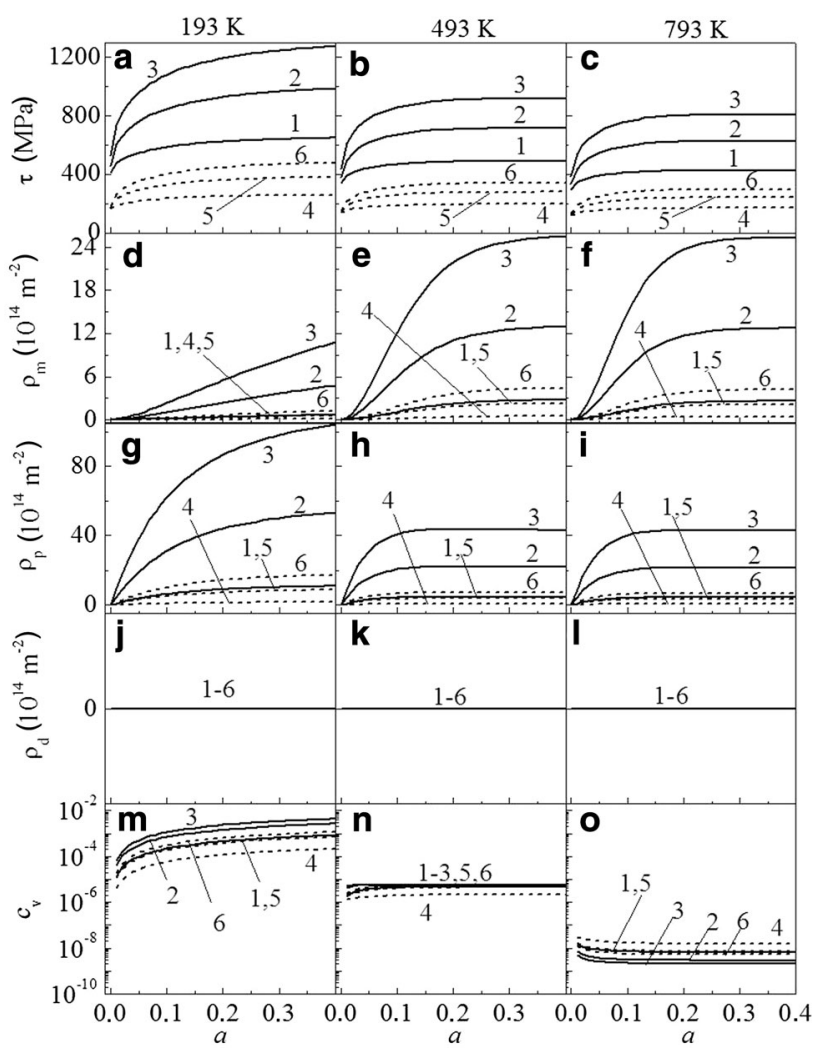

Fig. 1 Strain hardening curves $(\mathbf{a}-\mathbf{c})$ and the dependence of the density of shear-forming dislocations $(\mathbf{d}-\mathbf{f})$, prismatic loops $(\mathbf{g}-\mathbf{i})$, dipoles $(\mathbf{j}-\mathbf{l})$, vacancy concentration $(\mathbf{m}-\mathbf{0})$ on the degree of deformation for a copper-based alloy at different deformation temperatures. Distance between particles: solid line is $40 \mathrm{~nm}$; dashed line is $100 \mathrm{~nm}$. Diameter of particles (nm): 1, 4-1; 2, 5-5; 3, 6-10. The strain rate is $10^{-2} \mathrm{~s}^{-1}$ 
the deformation temperature (Fig. 1a-c, g-i, m-o). The density of shear-forming dislocations is determined by the ratio of the mechanisms of generation, annihilation, and relaxation transformation, each of which predominates in a certain temperature range (Fig. 1d-f).

Solution of the Eq. (1) allows us to establish the functional dependence of stresses on deformations (constitutive relations):

$\tau_{\mathrm{s}}=\tau_{0}+\tau_{1} \frac{a}{\left(a_{1}-\tau_{0} / G\right)+a}-\frac{\tau_{0} \tau_{1} / G}{\left(a_{1}-\tau_{0} / G\right)+a}$,

where $\tau_{0}, \tau_{1}, a_{1}$ are the semi-empirical parameters of approximation describing the material's properties. These parameters are given in Table 1.

\section{Mathematical model of plastic deformations}

Equilibrium equation allows you to determine the stresses in the pipe wall. In the plane axisymmetric case, this equation has the form [34]:

$\frac{\partial \sigma_{r r}}{\partial r}+\frac{\sigma_{r r}-\sigma_{\varphi \varphi}}{r}=0$.

The purpose of the study is to determine the stresses in the pipe wall. The inner wall loaded by the internal pressure $\left(r=R_{\text {in }}: \sigma_{r r}=-p\right)$. It is assumed that there is no external pressure $\left(r=R_{\mathrm{ex}}: \sigma_{r r}=0\right)$.

In the region of elastic deformation, the compatibility condition for stresses is fulfilled [35]:

$\frac{\partial}{\partial r}\left(r \frac{\partial}{\partial r}\left(\sigma_{r r}+\sigma_{\varphi \varphi}\right)\right)=0$.

Table 1 Parameters of the constitutive relations

\begin{tabular}{llll}
\hline Parameters & $\tau_{0}(\mathrm{MPa})$ & $\tau_{1}(\mathrm{MPa})$ & $a_{1}$ \\
\hline $\begin{array}{l}\Lambda_{\mathrm{p}}=40 \mathrm{~nm} \\
\delta=1 \mathrm{~nm}\end{array}$ & 341.62 & 163.65 & 0.027 \\
$\begin{array}{l}\Lambda_{\mathrm{p}}=40 \mathrm{~nm} \\
\delta=5 \mathrm{~nm}\end{array}$ & 380.93 & 362.12 & 0.024 \\
$\begin{array}{l}\Lambda_{\mathrm{p}}=40 \mathrm{~nm} \\
\delta=10 \mathrm{~nm}\end{array}$ & 443.88 & 511.39 & 0.023 \\
$\Lambda_{\mathrm{p}}=100 \mathrm{~nm}$ & 138.97 & & \\
$\delta=1 \mathrm{~nm}$ & & 66.54 & 0.034 \\
$\Lambda_{\mathrm{p}}=100 \mathrm{~nm}$ & 145.20 & & \\
$\delta=5 \mathrm{~nm}$ & & 147.26 & 0.028 \\
$\Lambda_{\mathrm{p}}=100 \mathrm{~nm}$ & 153.13 & & \\
$\delta=10 \mathrm{~nm}$ & & 206.91 & 0.026 \\
\hline
\end{tabular}

The principle of hardening of the material as a result of plastic deformation allows us to determine the maximum shear stresses [36]:

$\left|\sigma_{r r}-\sigma_{\varphi \varphi}\right|=\tau_{\mathrm{s}}(a)$.

The solution of the Eq. (1) with boundary conditions allows us to determine the stresses in the pipe wall. The stresses in the elastic zone $r<R_{\mathrm{pl}}$ are:

$$
\begin{gathered}
\sigma_{r r}=\frac{q R_{\mathrm{pl}}^{2}}{R_{\mathrm{ex}}^{2}-R_{\mathrm{pl}}^{2}}\left(1-\frac{R_{\mathrm{ex}}^{2}}{r^{2}}\right), \\
\sigma_{\varphi \varphi}=\frac{q R_{\mathrm{pl}}^{2}}{R_{\mathrm{ex}}^{2}-R_{\mathrm{pl}}^{2}}\left(1+\frac{R_{\mathrm{ex}}^{2}}{r^{2}}\right) .
\end{gathered}
$$

The stresses in the plastic zone $r<R_{\mathrm{pl}}$ are:

$$
\begin{aligned}
\sigma_{r r}= & \tau_{0} \ln \left(\frac{r}{R_{\mathrm{in}}}\right)+\tau_{1} \ln \left(\frac{r^{2}}{R_{\mathrm{in}}^{2}} \frac{R_{\mathrm{pp}}^{2} \tau_{0}+a_{2} G R_{\mathrm{in}}^{2}}{R_{\mathrm{pl}}^{2} \tau_{0}+a_{2} G r^{2}}\right) \\
& +\frac{1}{2} \frac{\tau_{0} \tau_{1}}{G a_{2}} \ln \left(\frac{R_{\mathrm{pl}}^{2} \tau_{0}+a_{2} G R_{\mathrm{in}}^{2}}{R_{\mathrm{pl}}^{2} \tau_{0}+a_{2} G r^{2}}\right)-p, \\
\sigma_{\phi \phi}= & \tau_{0} \ln \left(\frac{r}{R_{\mathrm{in}}}\right)+\tau_{1} \ln \left(\frac{r^{2}}{R_{\mathrm{in}}^{2}} \frac{R_{\mathrm{pl}}^{2} \tau_{0}+a_{2} G R_{\mathrm{in}}^{2}}{R_{\mathrm{pl}}^{2} \tau_{0}+a_{2} G r^{2}}\right) \\
& +\frac{1}{2} \frac{\tau_{0} \tau_{1}}{G a_{2}} \ln \left(\frac{R_{\mathrm{pl}}^{2} \tau_{0}+a_{2} G R_{\mathrm{in}}^{2}}{R_{\mathrm{pl}}^{2} \tau_{0}+a_{2} G r^{2}}\right)-p+ \\
& +\left(\tau_{0}+\tau_{0} \tau_{1} \frac{R_{\mathrm{pl}}^{2}-r^{2}}{R_{\mathrm{pl}}^{2} \tau_{0}+a_{2} G r^{2}}\right) .
\end{aligned}
$$

where $a_{2}=a_{1}-\frac{\tau_{0}}{G}$.

The boundary of the elastic and plastic deformation zones $R_{\mathrm{pl}}$ and stress on this boundary can be determined as:

$$
\begin{aligned}
q= & \left(\tau_{0}+2 \tau_{1}\right) \ln \left(\frac{R_{\mathrm{pl}}}{R_{\mathrm{in}}}\right)+\tau_{1}\left(1+\frac{1}{2} \frac{\tau_{0}}{G a_{2}}\right) \ln \left(\frac{\tau_{0} R_{\mathrm{pl}}^{2}+a_{2} G R_{\mathrm{in}}^{2}}{\tau_{0} R_{\mathrm{pl}}^{2}+a_{2} G R_{\mathrm{pl}}^{2}}\right)-p, \\
p & =\left(\tau_{0}+2 \tau_{1}\right) \ln \left(\frac{R_{\mathrm{pl}}}{R_{\mathrm{in}}}\right)+\tau_{0} \frac{R_{\mathrm{ex}}^{2}-R_{\mathrm{pl}}^{2}}{2 R_{\mathrm{pl}}^{2}} \\
& +\left(\tau_{1}+\frac{\tau_{0} \tau_{1}}{2 G a_{2}}\right) \ln \left(\frac{\tau_{0} R_{\mathrm{pl}}^{2}+a_{2} G R_{\mathrm{in}}^{2}}{\tau_{0} R_{\mathrm{pl}}^{2}+a_{2} G R_{\mathrm{pl}}^{2}}\right) .
\end{aligned}
$$

\section{Results and Discussion}

We consider the basic results of investigation of the stressstrain state of a pipe loaded with internal pressure. The walls of the pipe are made of a copper alloy strengthened with incoherent nanoparticles. The main parameters vary in the following ranges: the particle size being $\delta=5-10 \mathrm{~nm}$, the distance between the strengthening particles varying within $\Lambda_{\mathrm{p}}=40-100 \mathrm{~nm}$. The inner 
radius of the pipe was $R_{\text {in }}=0.1 \mathrm{~m}$ and outer radius $R_{\text {ex }}=0.105 \mathrm{~m}$.

Results of numerical simulation show that the radial stress $\sigma_{r r}$ value is negative. The absolute value of the radial stress $\sigma_{r r}$ on the inner wall is the maximum and equal to the applied pressure $\left|\sigma_{r r}\right|=p$. In approach to the outer wall radial stress monotonically decreases. On the outer wall of the pipe $\sigma_{r r}=0$. Tangential stress $\sigma_{\phi \phi}$ is always positive. It significantly exceeds the absolute value of the radial stress $\sigma_{r r}$. The signs of stresses indicate a compression in the radial direction and tension in the tangential direction.

Figure 2 presents the dependence between the stress $\sigma_{r r}$ and the radial coordinate for various values of applied pressure. One of the main characteristics of the stressstrain state of the pipe walls is the limits of elastic and plastic resistance. The elastic resistance limit matches the applied pressure $p_{1}$. Under this pressure, plastic deformation localizes on the inner pipe wall. The plastic resistance limit matches the applied pressure $p_{*}$, when plastic deformation reaches the outer pipe wall.

Calculation results show that the limit of the plastic resistance $p_{1}$ insignificantly exceeds the limit of the elastic resistance, such that $\left(p_{*}-p_{1}\right) / p_{*}<<1$. Therefore, the insignificant excess in the limit of the elastic resistance enables the plastic deformation in the most part of the pipe wall.

Figure 3 presents the dependence between the tangential stress $\sigma_{\varphi \varphi}$ and the radial coordinate for various values of applied pressure. Calculation results also show that within the plastic deformation zone, the tangential stress $\sigma_{\varphi \varphi}$ is monotonously increased, whereas within the elastic deformation zone, it monotonously decreases. The maximum value of the tangential stress $\sigma_{\varphi \varphi}$ is observed on the

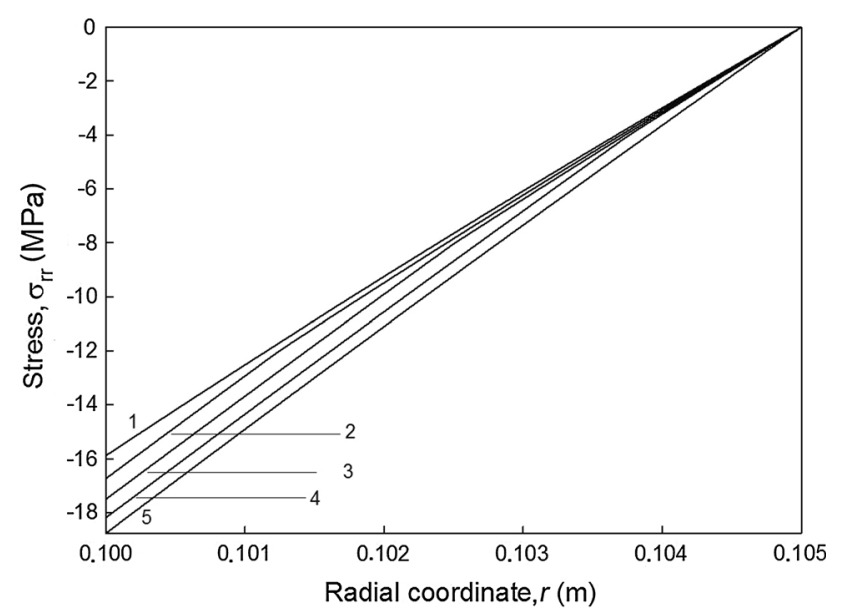

Fig. 2 Radial distribution of normal radial stress $\sigma_{r r}: \delta=1 \mathrm{~nm}, \Lambda_{\mathrm{p}}=40 \mathrm{~nm} ; 1-p=15.88 \mathrm{MPa} \quad\left(R_{\mathrm{pl}}=0.1 \mathrm{~m}\right)$, 2-16.73 (0.10125), 3-17.50 (0.1025); 4-18.18 (0.10375), 5$18.76(0.105)$

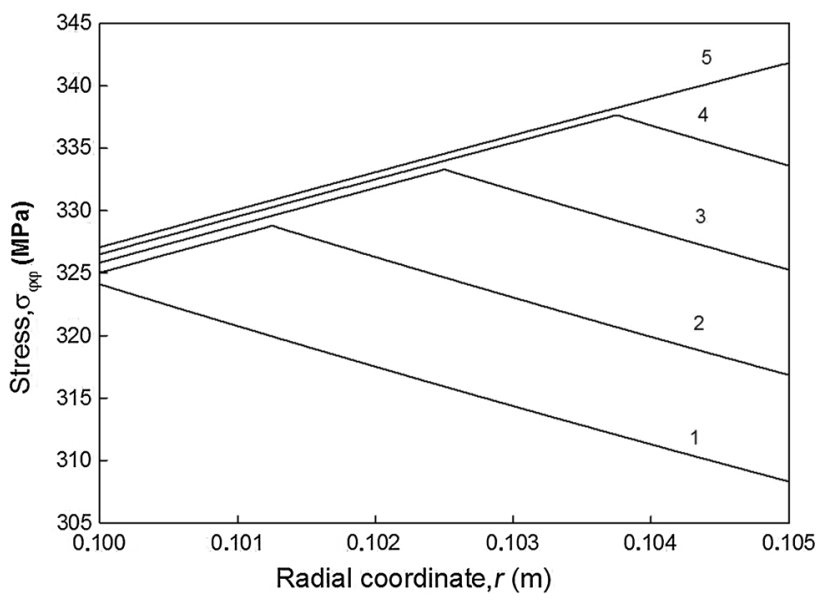

Fig. 3 Radial distribution of tangential radial stress $\sigma_{\varphi \varphi}: \delta=$ $1 \mathrm{~nm}, \Lambda_{\mathrm{p}}=40 \mathrm{~nm} ; \quad 1-p=15.88 \mathrm{MPa} \quad\left(R_{\mathrm{pl}}=0.1 \mathrm{~m}\right), 2-16.73$ (0.10125), 3-17.50 (0.1025), 4-18.18 (0.10375), 5-18.76(0.105)

boundary of the elastic and plastic deformation zones at $r=R_{\mathrm{pl}}$. When $p=p_{1}$, the plastic deformation zone is limited only by the internal boundary of the pipe wall, i.e., $R_{\mathrm{pl}}=R_{\mathrm{in}}$. Thus, the function of $\sigma_{\phi \phi}(r)$ becomes decreasing. When $p=p_{*}$, the boundary location of the elastic and plastic deformation zones coincides with the outer pipe wall, i.e., $R_{\mathrm{pl}}=R_{\mathrm{ex}}$. As a result, the function of $\sigma_{\varphi \varphi}(r)$ becomes increasing.

The applied pressure causes the deformation of the pipe wall. The radial distribution of the shear deformation intensity $a$ is presented in Fig. 4. The highest deformations localize on the inner pipe wall, where compressive stresses are the highest as well. As far as is concerned the deformation intensity in the inner pipe walls, it decreases with the increasing distance from the inner wall. The deformation of the outer pipe wall has the lowest values. On the

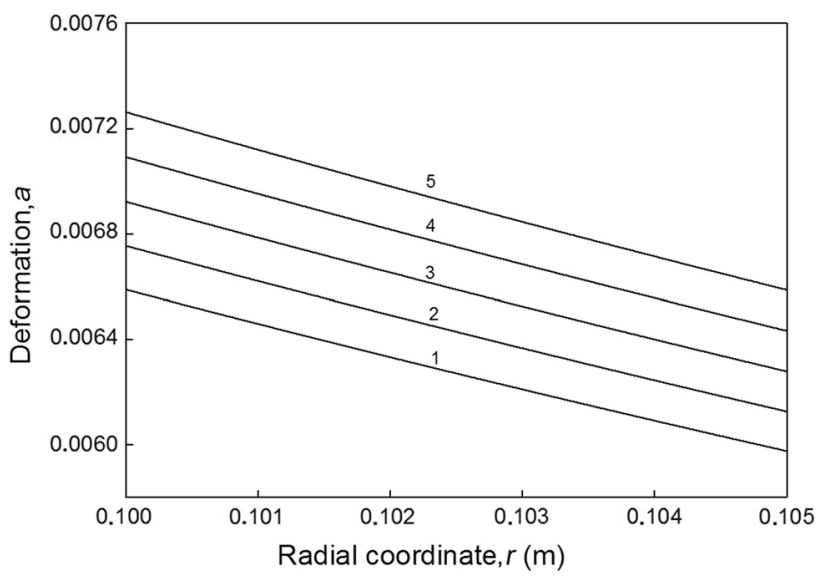

Fig. 4 Radial distribution of deformation intensity $a: \delta=$ $1 \mathrm{~nm}, \Lambda_{\mathrm{p}}=40 \mathrm{~nm} ; \quad 1-p=15.88 \mathrm{MPa} \quad\left(R_{\mathrm{pl}}=0.1 \mathrm{~m}\right), \quad 2-16.73$ (0.10125), 3-17.50 (0.1025), 4-18.18 (0.10375), 5-18.76 (0.105) 
boundary of the elastic and plastic deformation zones, the deformation intensity is determined by the maximum value of the elastic deformation, i.e., $a=\tau_{0} / G$.

The deformation intensity is determined by the value of the pressure applied. The higher the pressure applied to the pipe walls, the higher the deformation.

Let us analyze the defect structure appeared due to the pressure applied. Figure 5 demonstrates the radial distribution of the shear-forming dislocations density. Calculation results show that the highest values of shear-forming dislocations are observed in the vicinity of the inner pipe wall. The density of shear-forming dislocations decreases with decreasing distance to the outer pipe wall where it achieves the lowest values. The analysis shows that the increased applied pressure causes the growth in the density of shear dislocations.

The density of shear-forming dislocations is determined by the size of strengthening particles and the distance between them. The density of shear-forming dislocations is higher in alloys strengthened with coarse particles than that in alloys strengthened with fine particles. At small distances between the strengthening particles $\Lambda_{\mathrm{p}}$, this effect is the most pronounced. At larger $\Lambda_{\mathrm{p}}$ distances, the particle size effect on the density of shear-forming dislocations is the least pronounced.

Figure 6 contains the plots of the distribution on the wall thickness of the density of prismatic dislocation loops. The applied pressure induces stresses in the pipe wall which, in turn, generate the dislocation prismatic loops around the strengthening particles. This generation becomes stronger with increasing pressure applied to the inner pipe wall. At one and the same value of the location of the boundary of the elastic and plastic deformation zones $R_{\mathrm{pl}}$, the density of prismatic dislocation loops increases with the growing size of strengthening particles and decreases with decreasing distance between them.
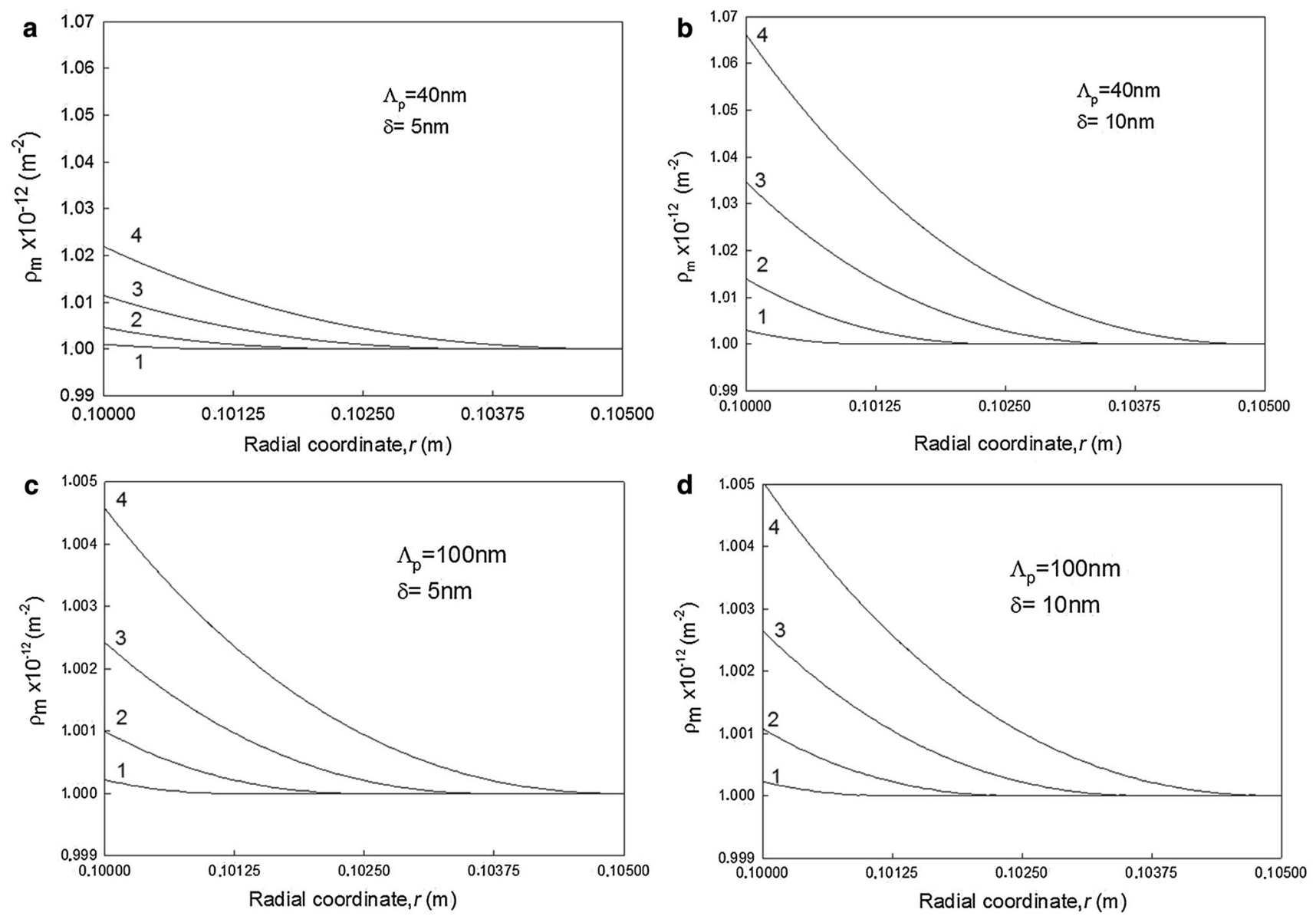

Fig. 5 Radial distribution of shear-forming dislocations density: a $1-\mathrm{p}=19.98 \mathrm{MPa}, 2-20.03,3-20.49,4-21.62$; b 1-23.73, 2-24.76, $3-25.84,4-26.98$; c $1-7.45,2-7.47,3-7.50,4-7.55$; d $1-7.91,2-7.99,3-8.01,4-8.20$ 

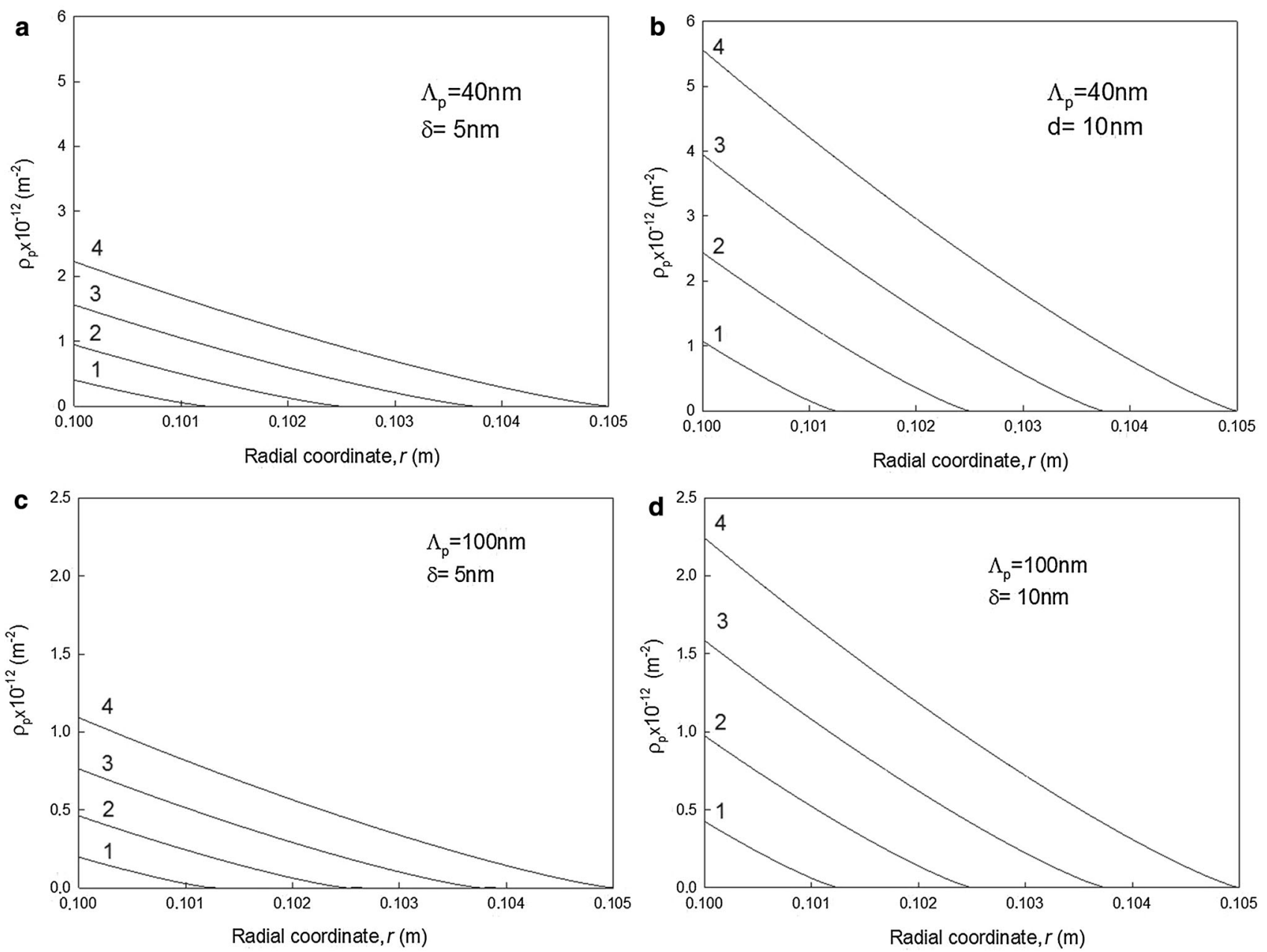

Fig. 6 Radial distribution of prismatic dislocation loops density: a $1-p=19.98 \mathrm{MPa}, 2-20.03,3-20.49,4-21.62 ; \mathbf{b} 1-23.73,2-24.76$, $3-25.84,4-26.98$; c $1-7.45,27.47,3-7.50,4-7.55$; d $1-7.91,2-7.99,3-8.01,4-8.20$

\section{Conclusion}

The plastic deformation of the pipe made of $\mathrm{Cu}$-based alloy hardened by incoherent nanoparticles and subjected to the uniform internal pressure was investigated. The limits of elastic and plastic resistance are determined. The insignificant excess in the limit of the elastic resistance enables the plastic deformation in the most part of the pipe wall. The absolute value of the radial stress $\sigma_{r r}$ on the inner wall is the maximum and equal to the applied pressure. Within the plastic deformation zone, the tangential stress $\sigma_{\varphi \varphi}$ is monotonously increased, whereas within the elastic deformation zone, it monotonously decreases. The maximum value of the tangential stress $\sigma_{\varphi \varphi}$ is observed on the boundary of the elastic and plastic deformation zones. The densities of shear-forming dislocations and prismatic dislocation loops are higher in alloys strengthened with coarse particles than those in alloys strengthened with fine particles. At small distances between the strengthening particles, this effect is the most pronounced.

\section{References}

[1] E. Orowan, in Proceedings of Symposium on Internal Stresses in Metals and Alloys (Institute of Metals, 1948), pp. 451-454

[2] V. Arnhold, K. Hummert, in New Materials by Mechanical Alloying Techniques, ed. by E. Arzt, L. Schultz (DGM Informationsgeselischaft Verlag, Oberursel, 1989), p. 263

[3] J. Rösler, R. Joos, E. Arzt, Metall. Trans. A 23, 5 (1992)

[4] J.H. Weber, R.D. Schelleng, in Dispersion Strengthened Aluminum Alloys, ed. by Y.-W. Kim, W.M. Griffith (TMS, Warrendale, 1988), pp. 467-482

[5] F. Dobes, K. Kucharova, A. Orlova, K. Milicka, J. Cadek, Acta Metall. Mater. 42, 1447 (1994)

[6] M.F. Ashby, Philos. Mag. 14, 132 (1966)

[7] M.F. Ashby, K. Johnson, Materials and Design, the Art and Science of Materials Selection in Product Design (Butterworth Heinemann, Oxford, 2002)

[8] R. Ebeling, M.F. Ashby, Philos. Mag. 13, 124 (1966) 
[9] P.B. Hirsch, F.J. Humphreys, in Physics of Strength and Plasticity, ed. by A.S. Argon (MIT Press, Cambridge, 1969), p. 189

[10] P.M. Hazzledine, P.B. Hirsch, Philos. Mag. 30, 6 (1974)

[11] F.J. Humphreys, P.B. Hirsch, Philos. Mag. 34, 4 (1976)

[12] F.J. Humphreys, A.T. Stewart, Surf. Sci. 31, (1972), pp. 389-421

[13] F.J. Hymphreys, J.W. Martin, Philos. Mag. 16, 143 (1967)

[14] F.J. Hymphreys, P.B. Hirsch, Proc. R. Soc. Lond. A 318, 1532 (1970)

[15] J.D. Embury, Metall. Trans. A 16, 12 (1985)

[16] T. Mori, T. Mura, Mater. Sci. Eng. 26, 1 (1976)

[17] I. Kröpfl, O. Vöhringer, E. Macherauch, Mech. Time Depend. Mater. 3, 1 (1999)

[18] P. Stobrawa, Z.M. Rdzawski, W. Głuchowski, J. Achieve. Mater. Manuf. Eng. 20, 1 (2007)

[19] R.A. Espinoza, R.H. Palma, A.O. Sepúlveda, V. Fuenzalida, G. Solórzano, A. Craievich, D. Smith, T. Fujita, M. López, Mater. Sci. Eng. A 498(1-2), 397 (2007)

[20] A.A. Zaitsev, V.V. Kurbatkina, E.A. Levashov, Rus. J. Non Ferrous Met. 49, 2 (2008)

[21] N.V. Novikov, G.P. Bogatyreva, R.K. Bogdanov, G.D. Il'nitskaya, M. Isonkin, M.A. Marinich, V.N. Tkach, M.A. Tsysar', N. Zaitseva, J. Superhard Mater. 33, 4 (2011)

[22] L.I. Tuchinskii, Kompozitsionnye materialy, poluchaemye metodom propitki (Composition Materials Obtained by Impregnation Method) (Metallurgiya, Moscow, 1986)

[23] K.I. Portnoi, B.N. Babich, Dispersno-uprochnennye materialy (Age-Hardened Materials) (Metallurgiya, Moscow, 1974)

[24] G. Cao, X. Chen, J.W. Kysar, D. Lee, Y.X. Gan, Mech. Res. Commun. 34, 3 (2007)
[25] N.A. Kulaeva, O.I. Daneyko, T.A. Kovalevskaya, V.A. Starenchenko, Vest. Tambov. Univers. Ser. Estestvennye i tekhnicheskie nauki (Bulletin of Tambov University. A series of natural and technical sciences), 21, 3 (2016)

[26] O.I. Daneyko, T.A. Kovalevskaya, S.N. Kolupaeva, N.A. Kulaeva, M.E. Semenov, Rus. Phys. J. 54, 9 (2012)

[27] T.A. Kovalevskaya, O.I. Daneyko, S.N. Kolupaeva, V.A. Starenchenko, Bull. Rus. Acad. Sci. Phys. 67, 6 (2003)

[28] T.A. Kovalevskaya, O.I. Daneyko, N.A. Kulaeva, S.N. Kolupaeva, Rus. Phys. J. 58, 3 (2015)

[29] T.A. Kovalevskaya, O.I. Daneyko, S.N. Kolupaeva, Deformatsiya i Razrushenie Materialov (J. of Deformation and Destruction of Materials). 2, 1 (2006), pp. 29-35

[30] O.V. Matvienko, O.I. Daneyko, T.A. Kovalevskaya, Rus. Phys. J. 60, 7 (2017)

[31] O.V. Matvienko, O.I. Daneyko, T.A. Kovalevskaya, Rus. Phys. J. 60, 2 (2017)

[32] O.V. Matvienko, O.I. Daneyko, T.A. Kovalevskaya, Rus. Phys. J. 60, 4 (2017)

[33] L.E. Popov, V.S. Kobytev, T.A. Kovalevskaya, Rus. Phys. J. 25, 6 (1982)

[34] J.R. Barber, Elasticity, 3rd edn. (Springer, Dordrecht, 2010)

[35] S.P. Timoshenko, J.N. Goodier, Theory of Elasticity, 3rd edn. (McGraw Hill, New York, 2010)

[36] J. Lubliner, Plasticity Theory (Dover Publications Inc., Mineola, 2008) 